\title{
The Contrast of Political Development and the Environment
}

\author{
Hamid $\mathrm{S}^{1} \&$ Roghayyeh $\mathrm{V}^{2}$ \\ ${ }^{1} \mathrm{Ph}$. D of Political Science, Department of Politics and Law, Science and Research Branch Islamic Azad \\ University, Tehran, Iran \\ ${ }^{2} \mathrm{Ph}$. D Student of Political Science, Department of Politics and Law, central Islamic Azad University, Tehran, \\ Iran \\ Correspondence: Hamid S, Ph. D of Political Science, Department of Politics and Law, Science and Research \\ Branch Islamic Azad University, Tehran, Iran. E-mail: hamedsarmadi2000@gmail.com
}

Received: February 12, 2018; Accepted: March 14, 2018; Published: May 19, 2018

\begin{abstract}
Political development has played an important role in the development of environmental law indirectly. Mechanism linking political development to environmental change is that political development provides an opportunity for different groups and civil society, including environmental advocacy groups, academic $\&$ scientific pressure groups to influence on political decisions and legislation. Establishing new academic disciplines particularly the environment international law, and trying to play a constructive role in the protection of the environment largely influenced by the pressure and influence of civil society. New social movements, particularly the Greens, diverted attention from economic development and class struggles to the environmental issues and through this; they were effective in the formation of convections and pro-environmental laws.
\end{abstract}

Keywords: political development, environment, environmental social movements

\section{Introduction}

Environmental and political issues in the developing world often have close relationship with each other. In this regard, environmental groups may consider the targets of their own time with pale positions of their own political band members. Governments may also use violent means to achieve the control of valuable natural resources. However, the issue isn't as simply as one of the ((good)) against ((bad)).

Local environmental groups are trying to defend their own local ecology and foreign governments or bad business interests are trying to destroy for their own interests. In fact, all the poor people or powerless people do not support environmental groups or don't wish to join them. Some of them earn their income through work in polluting industries or are applied by breaking ground for anti-ecological farming medals.

There is no doubt that 35 years after the Stockholm Environment Conference global members of environmental non-governmental organizations have been increased. "Now there are, tens of thousands" of them in developing countries.

Relatively speaking, many of them have been established in Latin America, India and East Asia; there are few In sub-Saharan Africa and much fewer than those in the Middle East and North Africa, the African Communist countries (China, Laos, Vietnam) and with regard to the development of civil society in these regions, it is not surprising the heterogeneous expanding the pro-environmental groups in the political developing world.

Environmental non-governmental organization in developing countries often attract the attention of most poor and powerless people such as youth and women which may completely reach to a common understanding that the current situation is unfavorable for their interests (fals bodra $1992: 311-316$ ), in short... the aim of this research is considering the contrast of political development and the environment.

\section{Environment}

The term environment can be called to the limited region or an entire planet and even into outer space that surrounds it. Biosphere term or the critical layer applied particularly by UNESCO corresponds to one of the widest definitions, including: human life environment or that part of the world, according to current knowledge of all human, life is in the continuation there. In fact, biosphere or critical layer is the thin layer which has surrounded the earth. Biosphere includes earth and thousands miles higher and depth of earth and oceans. 
Various definitions of environment have been presented in civil rights texts and international documents. Among them, the legal texts adopted by the Council of Europe Economic Community, on 27 June 1967 that says in the definition of the environment:

((Environment includes water, air, soil and internal \& external factors related to the life of every living creature)).

In the introduction of the United Nations Conference statement is announced to the governments about the human environment in Stockholm in 1972:

Human kind creates and forms his own environment, the environments which awards him physical survival, spiritual growth opportunities (social, moral and spiritual). Referring to "human forming environment" means that the man-made environment should also be considered, in such a way that it should be taken into account some part, or at least a major component of the natural environment. A notable example in this regard is article 1 in the UK Environmental Protection law Act 1990. Talking about pollution control, broshni presents a definition of environment and says: "environment comprises all or part of elements that make up natural environment, including water, air and soil either in the surface or in the depth naturally or man-made".

Another definition with more integrity about the environment has been applied in the Convention of civil liability of damages caused by dangerous acts in the environment. Its proposal has been adopted by the Council of Europe, which is a regional organization in Europe on 21 June 1993 in Lugano. According to Article 2 of Convention:

In terms of this Convention

Environment includes the following sections:

Renewable and non-renewable natural resources such as water, air, soil and all creatures and plants and mutual interaction of these factors on each other;

Properties that are part of the cultural heritage;

And specific perspectives;

Thus, man-made environment such as buildings, monuments, diverse buildings or specific landscapes and perspectives should be protected against damage as part of the environment (case et.al 2005, volume 1, 5-7).

\section{Political Development}

In recent decades, Political development has been one of the main axes of the social science literature. Now days, it can be seen overall attention in thinker's ideas and opinions \& political theorists toward the importance and complexity of development and political one which can't be seen in predecessor's perceptions (pie et.al, 2001). Classical thinkers such as Tocqueville, Marx, Durkem knew the development as a linear \& western process and had rather simplistic approach toward political development phenomenon (jaguaribe 1973, 26-35).

The failure of attempts to model European countries and inattention to thinker's social fields led this area to this understanding that the issue is Deeper and more extensive than the classics and predecessors think about it (badie 2000, 17-24). Today, unlike the past, the development is not seen as a one-dimensional phenomenon, but it is considered as a quite multifaceted, cohesive issue and political, social and cultural dimensions of development has special place along its economic dimension in endogenous development, human development and sustainable development issues and in almost all of these issues, "political development aspect" is considered seriously.

\section{Environment and Political Development in Rio Conference}

A distinct theory on rights and making decisions about the environment in international level was introduced with Rio de Janeiro Conference in 1992 about environment and political Development. For the first time, in this conference environment issue was placed in "development stability" perspective. Its basic was common general belief of most international community based on that there is a definite link between protecting the environment and promoting development. Hence, the ((Sustainable Development)) was placed at the forefront of policy-making discussions relating to environment.

General Assembly of the United Nations adopted holding International Conference about environment and development \& during that the UN Secretary General was asked to organize this conference introduction. Accordingly, the preparatory committee of the conference was formed with the active participation of representatives of all Member States and representatives of non-governmental \& international organizations \& within four meetings examined the topics which should be discussed in mentioned conference.

Subsequently, the UN Conference on Environment and Development began in Rio de Janeiro, Brazil in June 1992 with more than 30 thousand people from 176 countries, including 116 heads of state and representatives of 1400 active non-governmental international organizations in environment and 900 reporters and various topics related 
to the environment and development was discussed as current problem against human by $14^{\text {th }}$ June. Two other significant legal documents such as the UN Convention on climate change (climate change), New York (1992), Convention on Biological Diversity, Rio de Janeiro in 1992, which was prepared before conference, was opened for states signatures (case et.al 2005, volume 1,36).

Rio conference discussing environmental issue as a global problem emphasized on the necessity of coordination of developing countries trend with the environment protection and introduced environment protection as an important and international issue for future century and by proposing to establish an international environmental regulation to achieve sustainable development created a new evolution in developing process of the international law of environment. The conference gave more coherence to international community actions to protect environment in international institutions framework by strengthening existing institutions and new ones. Rio conference included three non-binding documents comprising final statement of the conference (an introduction and a bit and seven principles), Agenda 21 (a charter for the future) and adopted the principles of forest conservation. Rio Declaration of 1992 is considerable and notable from 2 perspectives: one, this text reflects the difference of developed and developing countries and another is considered attempt to give aim to the formulation and development process of environment international law. Thus, the legal principles contained in this Declaration, such as having physical and mental health and ability to adapt with nature (the environment right) (Article I), in this case it is necessary to note that the Rio Declaration on Environment and development, in its first article implies transition towards an approach in which the human is given priority toward environment in combination with the development. This principle says that human beings are ((in the center of concerns about the sustainable development)) and they deserve ((healthy and productive life in harmony with nature)) (Mohsen zadeh, 2009, 197).

Government's sovereignty in taking advantage of the natural resources under their jurisdiction in a fairly controlled way (principle two), the right for the development by compliance with the requirements of present and future generations (principle three), Eliminating Poverty (principle Five), noting to circumstances and needs of developing countries (principle six), more responsibilities of developed countries in environment protection (principle seven), exchanging information and new access of technologies (principle nine), reflect the views of developing countries. On the other hand, principles such as changing production and consumption patterns, population growth for their compatibility with environment and sustainable development (principle eight), people's right to access environmental information and the right of access to judicial and administrative authorities and courts and applying for penalties and compensation for environmental damage (principle ten), supporting economic free systems without imposing arbitrary and unjust actions for exploitation of others (principle twelve) and emphasis on the critical \& vital role of women cooperation in environment (principle twenty) reflect industrial and developed countries' ideas in environment protection and sustainable development in sustainable development process.

The second document of the Rio Conference, the basic principles statement of international consensus regarding conservation management and sustainable development of all types of forests consist of an introduction and fifteen articles. This document is a non-binding one and suggests governments how and based on what mechanism manages national forests which is considered the first global consensus on forests. Non-binding Document is action plan for the twenty-first century called agenda 21, adopted by other Conference in Rio in 1992, which considers the various aspects of environment and sustainable development and recommends solutions and executive methods for each of them by identifying existing problems. Agenda 21 was compiled in 40 chapters (115 threads) and 800 pages that were put in governments. In this document in the aspect of conservation and management of resources such as air, forest, water and strengthening national states legislative role is of elementary materials of this principle. In fact, agenda 21 is an action for protecting the global environment.

The effects of the Rio Conference on International Law of environment are as follow (pour hashemi \& arghand 2013, 33):

- The government should be concern about preserving and protecting the environment in economic, political, industrial growth and globalization development and address sustainable development as an approach in their own national development plans.

- The governments should mention ((principle of sustainable development)) in developing program rules and usual ones as well as the formulation of bilateral or multilateral legally binding documents.

- The governments should recognize the role of social groups, institutions, NGOs in preserving national, regional and global environment.

So the third period of the development of environmental international law process can be called realism, Comprehensive review, reforms and the emergence of different countries' conflicts about environment. In this 
course, international environmental rules \& regulations are evolved in sustainable development framework and they are reformed if necessary to be Coordinated with global realities and are applicable in practice as well as new regulations are formed. In this course, Agenda 21 as an international Action Plan was welcomed by a lot of countries and some were entered in countries' domestic rules. In this historical period, several international conventions were established on environmental protection \& the most important was Earth Summit +5 and Declaration of the World Summit on Sustainable Development in South Africa, Johannesburg, 2002.

Five years after the Rio Conference in 1992 \& based on decision taken at the conference by attending leaders and representatives of 185 countries to consider and analyze Rio conference achievements, to Evaluate the way of implementing its adopted agreements and decisions for necessary actions to prevent further damage of environment and to achieve sustainable development, it was held in the form of nineteenth Special session of the UN General Assembly from 23 to $27^{\text {th }}$ June 1997 in UN headquarter in new York. This session was ended following conflicts between developing countries and industrial ones in preparing financial resources and transition of needed technologies to developing countries and also dispute over renegotiate about Agenda 21 from one side, and conflicts between America and Europe Union to set a timetable for reducing emissions of greenhouse gases from other side, Without access to a conclusion and by issuing a statement entitled to run applications beyond Agenda 21.

In 2002, the fourth statement and non-legally binding document adopted in Johannesburg, South Africa. Johannesburg Declaration isn't seen as a successful statement for repeating Rio statement principles and not presenting legal approaches to preserve global environment. Although, on one hand, international law of environment in involved in conflicting between developed countries which destroyed their environment and earth to reach to an extreme economic growth and now they claim to preserve it $\&$ on the other hand, developing countries which don't have enough motivation to preserve environment in term of being costly and lack of access to modern technologies. Failure to reach agreement on the Copenhagen meeting in 2009 to review and revise the Kyoto Protocol is one of the problems facing contemporary environment international law. Rio summit +20 haven't been able to heal conflicts between developed and developing countries and haven't put a solution for economic growth and environmental protection paradox. So the development \& evolution of environmental international law in this historical period is owed to common understanding of developed and developing countries regarding preserving global environment (molaee, 2007, 278-280).

Political development impacts on environment rights evolution \& preserving \& promoting environment health; in a way that political open and decentralized space enables forming civil institutions, social movements and new \& competing ideas.

\section{The Contrast of Political Development and Environmental Issues from the Perspective of Social Movements}

In democratic countries, most of civil institutions, social movements and new ideas have focused on environmental issues. These groups have pressure on governments, large producing companies and industries' owners via education and information, establishment of new academic disciplines, building networks and new media, mobilizing resources to follow environmental rules and in this regard, they use the resort to appeal to public opinions. These groups activities isn't limited to attempt for following pre-existing rules but they try to propel governments to ordain new rules and regulations in internal level and to conclude new conventions and treaties in international level. Most of conventions related to environment \& establishing environment rights discipline has been the result of these groups pressure and attempts directly and indirectly. The main concern of social movements is changing in social relations and distributing political and economic power, most leaders and fans of social movements have accepted that changing in economic, social and political structures must be accompanied by changes in cultural and recognition structures and fields (moshir zadeh, 2011, 323-325). Hence, entering environment issue to social and legal issues is the result of movement's attempts and pro-environment civil groups. In fact, these groups and civil institutions have more chance to assert themselves and to influence policies.

Entering environment issue in political, legal and social issues is the result of the emergence of new social movements, especially the radical environmental movement. Prior to the emergence of these new movements, the labor movement and other movements and political parties were mainly focused on economy and sought to maximize their economic growth and their share of social and political benefits.

Environmental activism is seen as primarily a social movement. Social movements are considered ((a collective effort to transform the social structure)) which sometimes use ((ultra-characteristic methods)).

German sociologist, Lorenz von Stein entered ((social movement)) term in the academic issues related to popular political issue in his book, named the history of French social movement from 1789 up to now 1850. At first, this 
term embodied continuous and integrated process idea through which the whole worker class got to the collective consciousness and the power via that. When Von Stein wrote these, The Communist Manifesto (1848) Marx and Engels have recently mentioned this concept in their declaration based on that "All previous historical movements were movements of minorities, or in the interest of minorities. Proletariat movement had expressed Self-conscious, independent movement of mass majority is in favor of mass majority (Tilly, 2009, 24).

A distinctive form of following public policy was formed in the late eighteenth century in Western Europe and they were widely accepted in the early nineteenth century in Western Europe and North America, In the middle of that century it came together in an enduring set of elements, then evolved into a more slowly \& growing form, it developed in all over west and was named social movement. That political set combined three elements: 1 . Campaigns related to group claims which a aimed officials; 2. Range of functions related to allegedly plan, including the establishment of special purpose associations, public meetings, media statements and protests; 3 . Public representations of worthiness, unity, numbers and commitment of a Movement (Tilly, 2009, 28).

Social movements as we know today proliferated in the late eighteenth century in England, and it began his racing roots during the nineteenth century in Europe, North America and elsewhere. We should consider many related changes to understand the reason of this issue: powerful sovereignty but weak kingdom, people who organize against that sovereignty to claim, political elites Susceptible to such a claim who govern in the name of people. The start of forming Extensive literature and new communication medium which cause People isolated in space moves with a common song and become a member.

Social movements combine three types of claims: Program, identity, and status (validity). Claims about program include support or opposition regarding real or imagined actions of the objectives of movement claims (Tilly, 2009, 26-36).

Claims about identity include emphasis on this issue that ((we)), claimants form a unite power and you should consider us united.

Claims about status emphasize on links and similarities between movement activists and other political ones, such as deprived minorities and well-formed citizen groups or faithful supporters of the regime. Then for instance, they go through the status of other political activists by deporting refugees or taking their citizenship rights. Claims about program, identity and status adapt with various codes created from particular political history of that regime.

The relative importance of the claims related to the program, identity and status is different within the social movements, current claimants within those movements, and among various courses of movement. In fact, a considerable amount of discussion may focus within the social movements around the relative importance of different claims.

Democratization and political development will strengthen the formation of social movements. Democratization means forming regimes whose characteristics are existing broad and equal citizenship, Binding consultations with citizens about government policies, Personnel and resources, and a minimum amount of protection for citizens against arbitrary acts of government agents. In fact, the Democratization will limit the scope of effective popular collective action. For instance, democratic institutions prevent violent popular uprisings. However, empowering citizens through competitive elections and other forms of consultations are combined with the support of civil liberties such as creating association and holding assemblies to flow popular claims into forms of social movements.

Shapes, personnel and the claims of social movements evolve throughout history. Three distinctive but interacting resources cause diversity in place and time to make changes in social movements. First, the general political environments (democratization and de-democratization) are involved in the relative autonomy of social movements and affect its fortune. Second, in the interaction which occurs within social movements (e.g., interactions between demonstrators and police), changes can occur as a result of continuous innovation, dialogue and conflict in a way of growing. Third, participants in social movements - including not only Activists, but officials and other targets of claims communicate with each other by borrowing and adapting ideas, personnel, support, rhetoric, and practice models. They also borrow, adapt and innovate while competing to get privilege and sponsor. This borrowing and adaptation are often occur in far distances and between social movements completely isolated from each other. The changes in political environments, growing Changes within the realm of social movements and transition between movements in interacting with each other create considerable variation \& change in the nature of social movements. Pro-environment movements and green parties that are highlighted in the past two decades have given a marvelous range of interpretations about the depth and nature of the environmental crisis we are facing and how to save ourselves from effects. 
Radical environmental movements reject the communities' belief to the current economic growth and they know this as one of the main reasons of most issues related to environment in today's world because all perishable and non-renewable resources are exploited greatly. Greens criticize competitive and individualism moods of these communities which lead to granularity of community and the most important lead to deep alienation from nature. They criticize dominant intellectual culture \& customs of the West communities why the see justifications for exploitative considerations toward nature in the west political theory and philosophy which has been changed to institutions in these communities. Hence, they blame these political \& ideological communities and organizations for the current crisis of environment. The greens say that without a fundamental change in this regard the deep crisis that we face in environment issue will be worse (Peterson, 2012, 344).

In other words, the greens stand up against assumptions behind social images which industrial modern communities' ideologies lay ahead, specially the images which allow free market. The greens are placed for a community consists of rational and autonomous individuals with a market providing a context for economic affluence to have safe social relations and beneficial from both sides, in the present society, which is way far away from that ((Medina misguided)) sees, we, its members go through the destruction of earth. Following economic growth without reason \& making sure about human capacity strengthen this issue to repair more evident every day damages which industrial modern community bring for natural environment. Most followers of the green movement think that the gap between communities as it is and as the way it should be, are deep and their hostility with technology and industrialism believing organs which are taken into account as a dominant basic design, is led from here.

\section{Conclusion}

In general, in any country where there is a higher degree of political development, pro-Environmental groups, including social movements and pressure groups, the green parties and the scientific community can better force the governments to enact and enforce suitable environmental rules. In this regard, democratic countries have better environmental performance indicators. In fact, political development cause Political decision exit from focused, personal, arbitrary, secretive and behind the scenes, irrational and destructive mode and is based on the participation of different groups, including pro- environment groups, Thus enabling legislation to protect the environment. Political development provides open space in community and creates reasonable grounds to criticize and supervise the activities of governments and companies. In political closed space in which governments and officials close all discussion and cooperation facilities and take all the powers, the possibility of forming movements, civil institutions and free press and non-governmental groups are removed and politicians with having resources prevent diffusing proper and knowledgeable news to public. Instead, they mobilize public behind their destructive irrational policies to suppress any types of oppositions. The policies lead to irreversible effects in various areas including environment.

Besides what was said political development ensures universities \& scientific centers independency and it will be effective to open space for free academic discussions \& away from governmental orders in developing new disciplines related to environment (including environment rights). Developing these disciplines provides the possibility of professional and deliberate political decision on environmental issues.

\section{References}

Badie, B. (1997). Political development, translated by naghib zadeh ahmad, Tehran, ghoomes publication.

Case, A. (2005). Environment law, translated by habibi, mohammad hasan, $2^{\text {nd }}$ edition, Tehran, Tehran university publication.

Fals, B. O. (1992). "Social Movements and Political Power in Latin America" in A, Escobar and S, Alvarez, The Making of Social Movements in Latin America Identity: Strategy and Democracy, Boulder, CO, Westview, pp. 303-316.

Jaguaribe, H. (1973). Political Development: a general Theory Latin America case study, New York, Harper \& Row publishers.

Mohsen, Z., \& Ahmad, A. et al. (2009). Environment law, theories and practices, Tehran, khorsandi publications.

Molaee, A. (2009). Essay, "Environmentally sustainable development principles in the constitution of Islamic republic of iran" in environment book, theories and practices, Law Office and parliament affairs of EPA.

Moshir, Z. H. (2002). An introduction to the theory of social movements, Tehran, Imam Khomeini Research Institute.

Peterson, M. (2012). The green politics field, translated by talebi, rooho llah, in perchil scott et.al, theories of 
international relations, translated by moshir zadeh, homeira \& talebi, roho llah, Tehran, mizan pulication.

Pie, L. (1991). Political culture, political development, translated by majidi majid, Encyclopedia, no $5 \& 6$.

Pour, H., Seyed A., \& Arghand, B. (2013). Environmental international law, Tehran, dadgostar publication.

Tilly, ch. (2009). Social movements, translated by morshedi zad, ali, Tehran, imam sadegh university publication.

\section{Copyrights}

Copyright for this article is retained by the author(s), with first publication rights granted to the journal.

This is an open-access article distributed under the terms and conditions of the Creative Commons Attribution license (http://creativecommons.org/licenses/by/4.0/). 